\title{
Experimental Study on Viscoplastic Property of Unsaturated Reticulate Red Clay Used as an Engineered Barrier
}

\author{
Chuang Zhang, ${ }^{1,2}$ Jian-Zhong $\mathrm{Li}^{1,2}$ and Yong $\mathrm{He} \mathbb{i}^{1,2}$ \\ ${ }^{1}$ Key Laboratory of Metallogenic Prediction of Nonferrous Metals and Geological Environment Monitoring (Central \\ South University), Ministry of Education, China \\ ${ }^{2}$ School of Geosciences and Info-Physics, Central South University, Changsha 410083, China
}

Correspondence should be addressed to Yong He; heyong18@csu.edu.cn

Received 12 February 2020; Revised 29 July 2020; Accepted 6 August 2020; Published 1 September 2020

Academic Editor: Nicoló Colombani

Copyright ( 92020 Chuang Zhang et al. This is an open access article distributed under the Creative Commons Attribution License, which permits unrestricted use, distribution, and reproduction in any medium, provided the original work is properly cited.

In this study, to explore the feasibility of a compacted red clay as an engineered barrier in landfills, the viscoplastic property of remodeled unsaturated reticulate red clay was studied through a series of triaxial tests. According to the deviatoric stress-axial strain curves obtained through loading tests with varying strain rates and under different conditions, the viscoplastic parameter $\beta$ of remodeled reticulate red clay was obtained. The effects of different matric suctions and net confining pressures on the viscoplasticity of unsaturated reticulate clay were analyzed. The test results showed that remodeled reticulate red clays with different degrees of saturation have similar viscoplastic properties, and their stress-strain curves are all isotach. The stiffness of unsaturated reticulate red clay increased with increasing confining pressure and matric suction. The relationship between $\beta$ and the net confining pressure can be described using a linear equation. The $\beta$ value of the specimens increased with increasing matric suction under a constant net confining pressure. A similar linear relationship was observed between $\beta$ and the matric suction. These relationships are explained considering the loading rate effect mechanism.

\section{Introduction}

Landfills can potentially cause severe environmental pollution [1]. Engineering practice has shown that the key to ensuring the environmental safety of a landfill is to control the diffusion of contaminants in the underlying soil. Installation of an engineered barrier (or liner system) is the key measure to prevent or mitigate such diffusion [2]. However, vertical engineered barriers and horizontal liners are affected by different geo-stresses in different locations in the landfill and are dependent on landfill depth. In addition, time effects can arise when the barrier or liner is subjected to geo-stress for a prolonged period of time. With the continuous addition of municipal solid waste, the vertical load on a horizontal liner system increases gradually. As a result, engineered barriers and liners can undergo creep deformation. Furthermore, during long-term operation of a landfill, the consolidation, seepage, biological and chemical processes, gas migration, and their coupling effects in the landfill produce different stress histories in the vertical engineered barrier and the horizontal liner system.

Engineered barriers in landfills are often placed in an unsaturated condition to avoid direct contact with the atmosphere and changes in the groundwater level $[3,4]$. Because of their low permeability, self-healing through swelling, low cost, and high adsorption capacity, clays such as red clays (or laterite) and bentonite are widely used in seepage control systems in contaminated sites [5-7]. The viscoplastic property of compacted clay is a relevant factor that must be considered in the design and operation of engineered barriers and liner systems.

The viscoplasticity of soil is a significant issue in soil mechanics and geotechnical engineering. With the development of research on the viscoplasticity of soil, several theories have been proposed related to creep deformation [8], loading rate effects [9-11], and constitutive modeling $[12,13]$ that have greatly promoted the development of soil mechanics. Some researchers have proposed parameters for describing 
clay viscoplasticity $[14,15]$. Some viscoplastic parameters focus on the creep properties of clay [16]; others focus on the loading rate effects of clay [17, 18]. A number of researchers [19-25] have reported the considerable effects of loading rate on soils, through stress-strain experiments conducted in a laboratory. The effects of a variable strain rate on the stress-strain relation, creep deformation, and stress relaxation were significant. Alonso et al. [26] presented the first comprehensive elastoplastic model to describe the load collapse characteristics of unsaturated soils. The model is known as the "Barcelona basic model" (BBM). In the BBM, it is assumed that the slope of the normal consolidation line (NCL) is a suction function, and the yield surface appears in the space of net stress and suction. Wheeler et al. [27] further detailed the BBM model. Fredlund and Morgenstern [28] established models using independent stress state variables. These constitutive models used net stress and suction to simulate the behavior of unsaturated soils found to be the most satisfactory for engineering purposes [29-34]; however, these models have some disadvantages [35]. The Sekiguchi model $[36,37]$ is one of the earliest to model the viscoplastic behavior of soils. This model could demonstrate creep deformation and creep rupture under undrained conditions. However, it has a restriction in explaining the infinite deformation behaviors from inviscid to viscous. The majority of Perzyna's overstress-based models $[38,39]$ assumed that the viscoplastic strain rate is only associated with the current stress state, rather than the stress history and stress rate, indicating that the consistency rule is ineffective. These models cannot indicate tertiary creep and creep failure. Gennaro and Pereira [40] presented a viscoplastic constitutive model for unsaturated geomaterials. The model indicated double effects of strain rate and suction on the viscoplastic behavior of geomaterials. Several researchers [41-45] investigated the effect of strain on the mechanical behavior of soil. However, the research was restricted to few soil types (sandy soils, low plasticity soils, stiff soils) and a small range of strain rates. Zhu et al. [46] conducted undrained creep tests to illustrate the stress-strain behavior of stiff soils at different strain rates. Tatsuoka et al. [47] and Yamamuro et al. [48] studied the stress-strain behavior of sands by conducting triaxial compression tests on loose and medium dense sand at high strain rates. The results showed that the strain rate has an important effect on the shear band orientation and the relevant destruction mechanism of sand. The shear strength and deformation features of clayey soil under monotonic and cyclic loading conditions have been studied by several researchers [49-53]. Whitman and Healy [54] conducted triaxial tests on Ottawa sand, Fort Peck sand, and Camp Cooke sand; the test results indicate that there is a critical loading rate for the three types of sand. When the loading rate is less than the critical rate, the compressive strength decreases with an increase in the loading rate; beyond the critical rate, the compressive strength increases as the loading rate increases. The plane strain compression and triaxial compression tests were conducted under a certain confining pressure by Peng et al. [55]. The test results showed that the stress-strain relationship of the sand was almost unaffected when the loading rate was constant. However, when the strain loading rate
TABle 1: Physical properties of reticulate red clay.

\begin{tabular}{lc}
\hline Properties & Value \\
\hline Water content $(\%)$ & 24.3 \\
Density $\left(\mathrm{g} / \mathrm{cm}^{3}\right)$ & 1.9 \\
Specific gravity & 2.71 \\
Liquid limit $(\%)$ & 40.8 \\
Plastic limit $(\%)$ & 22 \\
Cohesion $(\mathrm{kPa})$ & 59 \\
Friction angle $\left(^{\circ}\right)$ & 20.3 \\
Effective size $(\mathrm{mm})$ & 0.047 \\
Control size $(\mathrm{mm})$ & 0.694 \\
Optimum moisture content $(\%)$ & $20 \pm 1$ \\
Maximum dry density $\left(\mathrm{g} / \mathrm{cm}^{3}\right)$ & $1.75 \pm 0.05$ \\
\hline
\end{tabular}

changed abruptly during loading, the corresponding stressstrain curve increased or decreased suddenly. Li et al. [56] used computer-controlled strain triaxial apparatus and precise LDT strain measurement methods to perform different constant strain rate loading tests on Japanese Kitan clay, Ohi-machi clay, and Fujinomori clay at different loading stages. The tests showed that the viscoplastic properties of the three clays exhibited isochronic properties.

Saturated and unsaturated soils should be evaluated during the analysis and design of geotechnical engineering projects, because most parts of the world are covered by unsaturated soil, which could be converted to saturated soil by climate and groundwater changes [57-59]. In the early study of unsaturated soil mechanics, researchers affirmed that the loading rate had a significant effect on the stressstrain behavior of unsaturated soils. Veyera [60] used three types of clays and three types of sands to study the loading rate effect of unsaturated soils under high loading rates. The results of the study showed that under high-speed loading conditions, the loading rate effects of unsaturated soils were obvious. Martin et al. [61] conducted similar tests with sand. The test results showed that the loading rate effect existed in unsaturated sand. Rojas and Mancuso [62] conducted a triaxial test on the suction control of pyroclastic silt, demonstrating that when the suction was small, the loading rate effect was not evident, and when the suction was large, the loading rate effect was very prominent. David and Fredlund [63] studied the stress-strain features of unsaturated soils under different loading rates and established a theoretical model for forecasting the shear deformation of unsaturated soils. Huat et al. [64] used three different loading rates to study the effect of the loading rate on unsaturated soils. The experimental results showed that under the constant suction condition, the unsaturated soil showed an obvious loading rate effect. Based on the Barcelona model, Gennaro and Pereira [65] proposed a viscoplastic theory model that could consider the loading rate effect. Li et al. [66] studied the creep and loading rate effects of unsaturated soils with different water contents and proposed a three-element model that can be used to simulate the loading rate effect of unsaturated soils. 


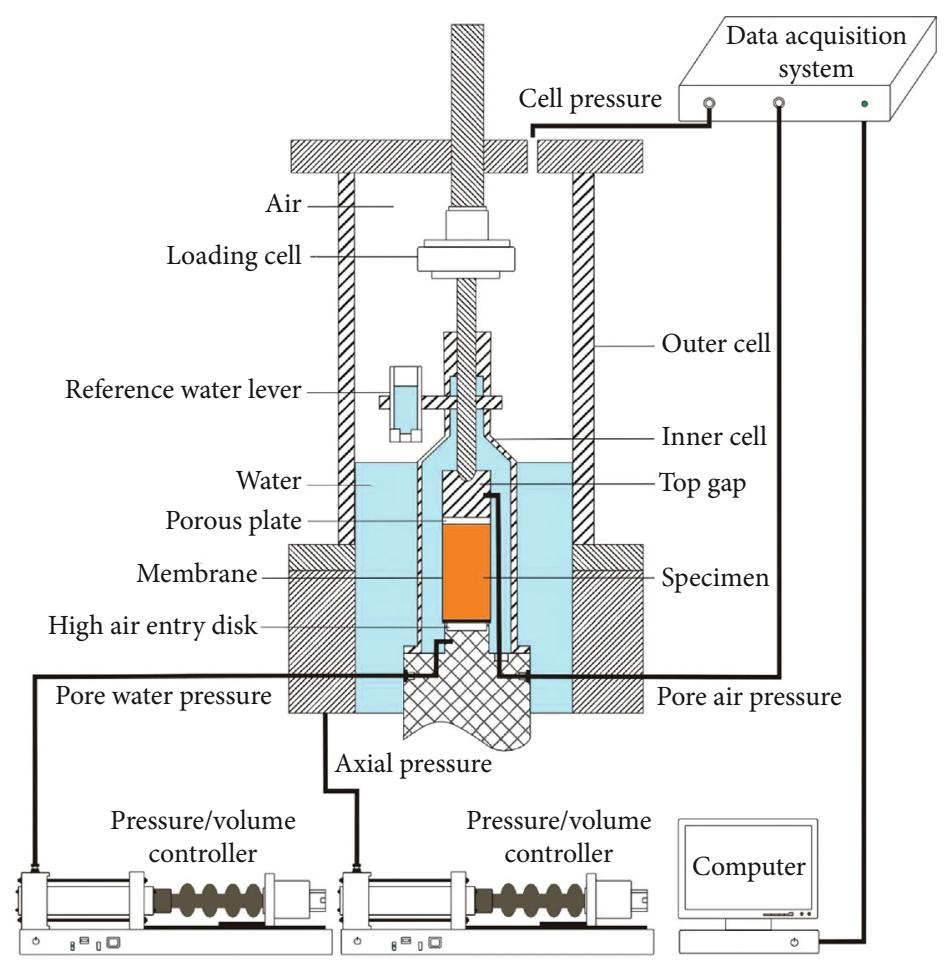

FIGURE 1: The GDS unsaturated triaxial test system.

This study attempts to illustrate the loading rate effect of unsaturated reticulate red clay through triaxial tests. Loading rate effect tests with constant net confining pressure and variable matric suction and with constant matric suction and variable net confining pressure were conducted by the unsaturated triaxial instrument. The viscoplastic parameter $\beta$ of remolded reticulate red clay was calculated according to the stress-axial strain curves under different test conditions. The effects of different matric suction and net confining pressure on the viscoplasticity of unsaturated reticulate red clay were analyzed. The innovation of this study is the viscoplastic parameter $\beta$ to describe the viscoplasticity of reticulate red clay. The value of $\beta$ is obtained via variable strain rate loading tests. The loading rate effect of soil is a manifestation of soil rheology. Therefore, the viscoplastic parameter $\beta$ provides an important theoretical basis for analyzing the effect of loading rate on the viscoplasticity of the unsaturated reticulate red clay.

\section{Materials and Methodology}

2.1. Materials. Reticulate red clay specimens used for the experiments were sampled from the Yuelu Mountain of Changsha City in China. This red clay can be used as a horizontal (liner) or vertical engineered barrier in landfills, suffering upper load of municipal solid waste or surrounding soil pressure. The physical properties of reticulate red clay are summarized in Table 1.

2.2. Test Apparatus. The standard GDS unsaturated triaxial apparatus was adopted in the experiment. The experimental setup is shown in Figure 1. The main apparatus consisted of a pressure chamber, a pressure system, and a measurement and collection system. The peripheral pressure, axial pressure, pore air pressure, and pore water pressure could be controlled independently and arbitrarily. The air pressure and water pressure of the specimens were controlled using the perforated plate in the specimen cap and the ceramic plate in the specimen bottom, respectively $[67,68]$. The test range and accuracy of GDS unsaturated triaxial apparatus are 1.0 $\mathrm{MPa}$ and $0.1 \mathrm{kPa}$, respectively.

\subsection{Test Procedures}

2.3.1. Specimen Preparation. To avoid the unevenness of undisturbed specimens, remolded specimens were used in this investigation. The specimen was pretreated through air-drying and grinding using a mortar, and the powder was passed through a 2-mm sieve. Subsequently, an amount of soil was sprayed with distilled water and placed in a plastic bag for $24 \mathrm{~h}$ for homogenization of the specimen. Subsequently, the soil powder was put into the cylindrical mold (Figure 2(a)), applied pressure to the soil through a round pestle rod (Figure 2(a)) by a universal testing machine (Figure 2(b)). The pressure rate was controlled at $0.2 \mathrm{~mm} / \mathrm{min}$. After the specimen was compacted to the design height, the compaction is stopped, and the universal testing machine stopped at this position for $1 \mathrm{~h}$ to make the deformation of the specimen stable, and then take out the specimen (Figure 2(c)). The diameter and height of the remolded soil specimens were $61.8 \mathrm{~mm}$ and $125 \mathrm{~mm}$, respectively. The remolded specimens used for experiments had a dry density of $1.6 \mathrm{~g} / \mathrm{cm}^{3}$ and a moisture content of $24 \%$. The formed specimens were saturated using the vacuum saturation method for 


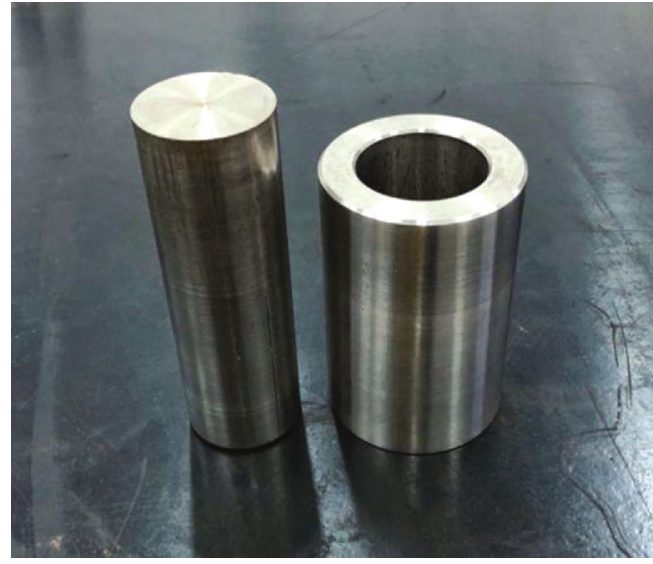

(a)

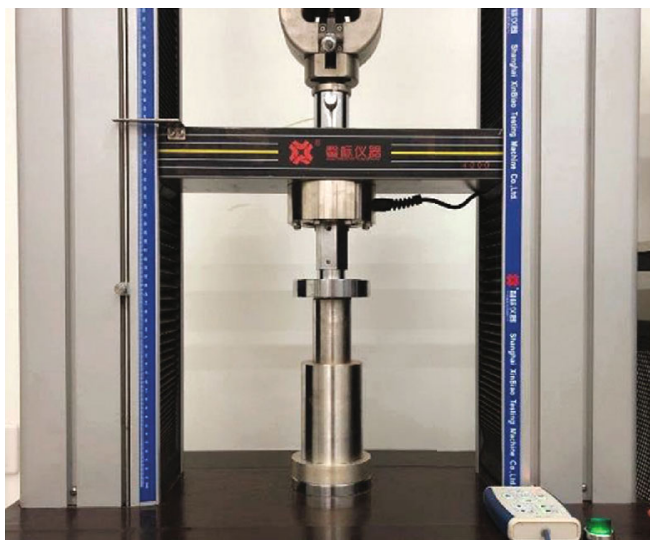

(b)

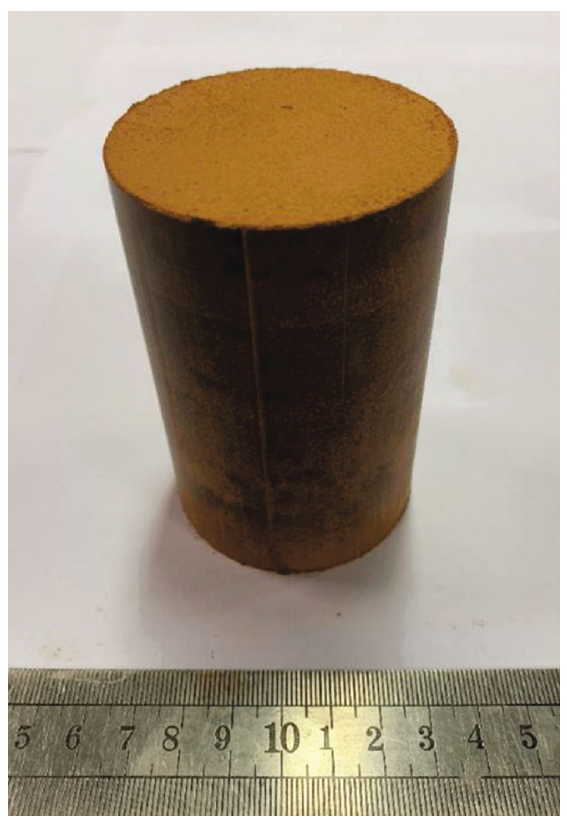

(c)

FIGURE 2: The compaction process (a) Mold. (b) Universal testing machine. (c) Remolded specimen.

TABLE 2: Specifications of the viscoplastic tests.

\begin{tabular}{lcc}
\hline Specimen & $\sigma_{\mathrm{n}}(\mathrm{kPa})$ & $s(\mathrm{kPa})$ \\
\hline R1-1 & 100 & 0 \\
R1-2 & 200 & 0 \\
R1-3 & 300 & 0 \\
R1-4 & 400 & 0 \\
R2-1 & 400 & 0 \\
R2-2 & 400 & 50 \\
R2-3 & 400 & 100 \\
R2-4 & 400 & 200 \\
R3-1 & 100 & 0 \\
R3-2 & 100 & 50 \\
R3-3 & 100 & 100 \\
\hline
\end{tabular}

at least $24 \mathrm{~h}$. The saturation was completed when the degree of saturation reached approximately 95\%. The specimens were removed from the container and placed in the triaxial apparatus for the tests.

2.3.2. Loading Rate Effect Tests. The loading rate effect experimental scheme is shown in Table 2. $\sigma_{\mathrm{n}}$ is the net confining pressure $\left(\sigma_{\mathrm{n}}=\sigma_{3}-u_{a}\right), s$ is the matric suction $\left(s=u_{a}-u_{\mathrm{w}}\right)$, $\sigma_{3}$ is the confining pressure, $u_{a}$ is the pore air pressure, and $u_{\mathrm{w}}$ is the pore water pressure. All experiments were conducted at a constant temperature of approximately $22^{\circ} \mathrm{C}$. The experiments were performed through the following steps.

(1) Installation of specimen: first, the ceramic plate on the base of the pressure chamber was saturated, and the air in the water pressure pipeline was exhausted. The saturated specimen was sheathed with a rubber 


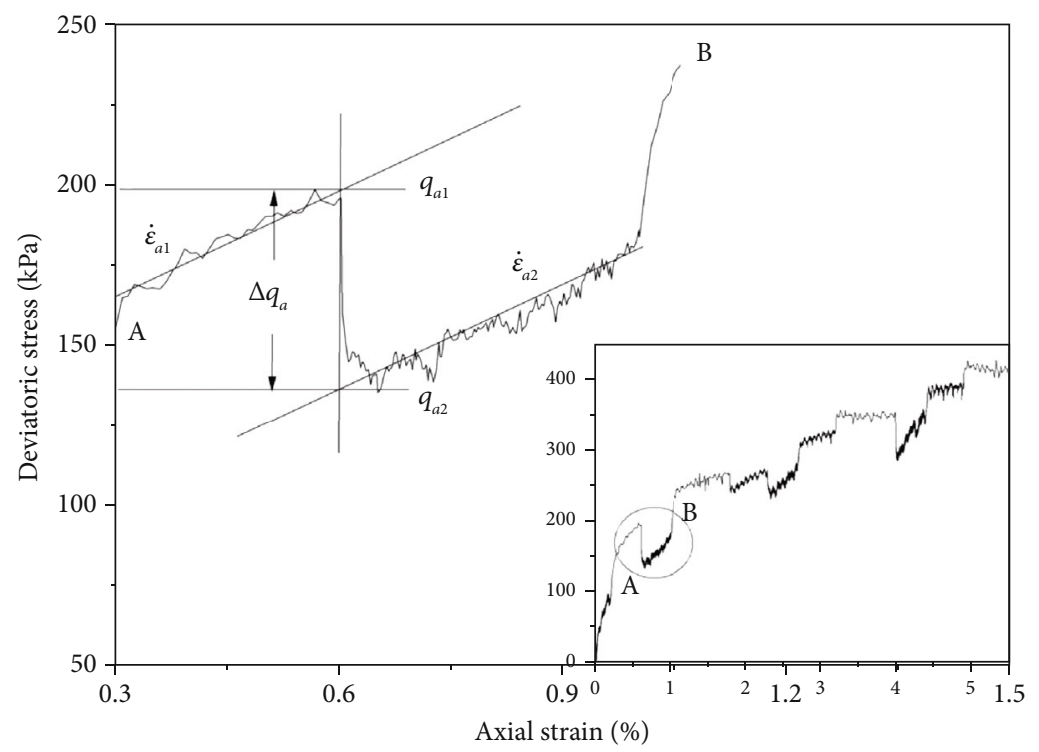

FIGURE 3: Method of obtaining $\Delta q_{a}, q_{a 1}, q_{a 2}, \dot{\varepsilon}_{a 1}$, and $\dot{\varepsilon}_{a 2}$.

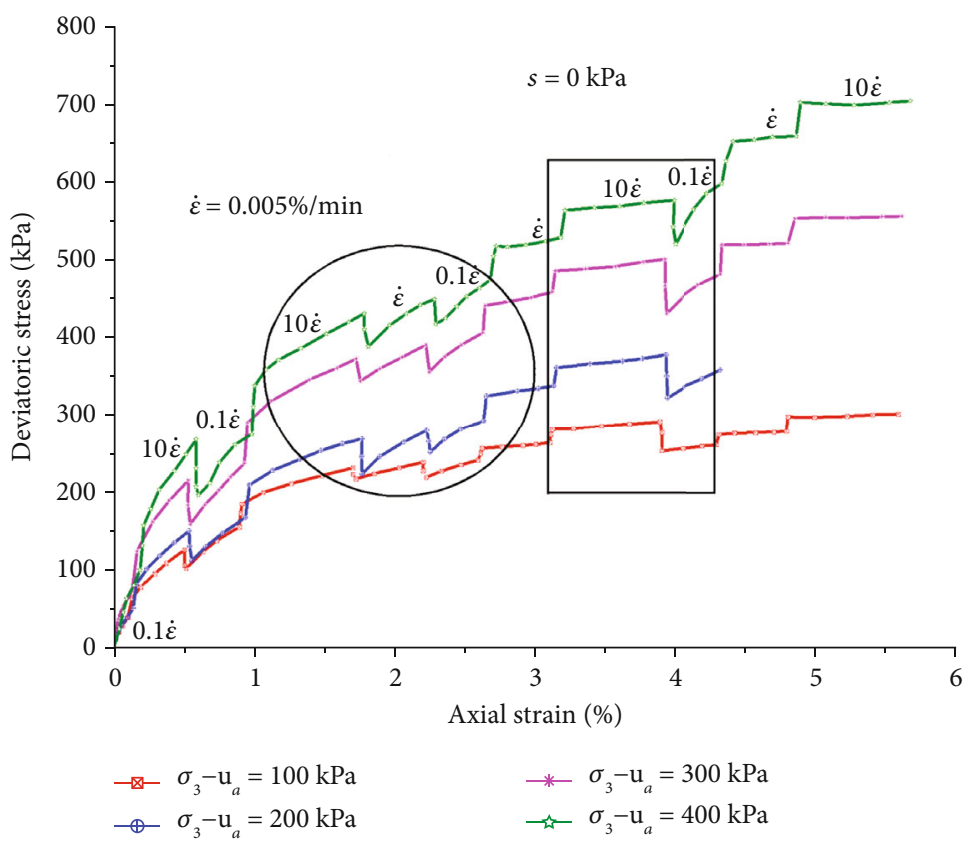

FIgURE 4: $\left(\sigma_{1}-\sigma_{3}\right)-\varepsilon_{a}$ summary curves $(s=0 \mathrm{kPa})$.

membrane and fixed on the ceramic plate. A permeable stone and a specimen cap were placed on top of the saturated specimen, connected by a rubber membrane. The instrument was installed and checked for leaks, and the instrument reading was cleared.

(2) Isotropic consolidation: consolidation was performed by applying a confining pressure to the target value instantaneously. The water in the specimen was discharged from the ceramic plate. The balance standard of consolidation is that the volume change of the back pressure within $24 \mathrm{~h}$ is less than $0.05 \%$ of the specimen volume [69].

(3) Matric suction equilibration: the matric suction was applied and controlled through the axis-translation technique. The pore water pressure applied for the unsaturated specimen was $0 \mathrm{kPa}$; the matric suction was equal to the pore air pressure $u_{a}$. The net confining pressure $\sigma_{\mathrm{n}}$ was maintained at a constant value, and the pore air pressure $u_{a}$ was increased, until the target values were reached. When the volume of 


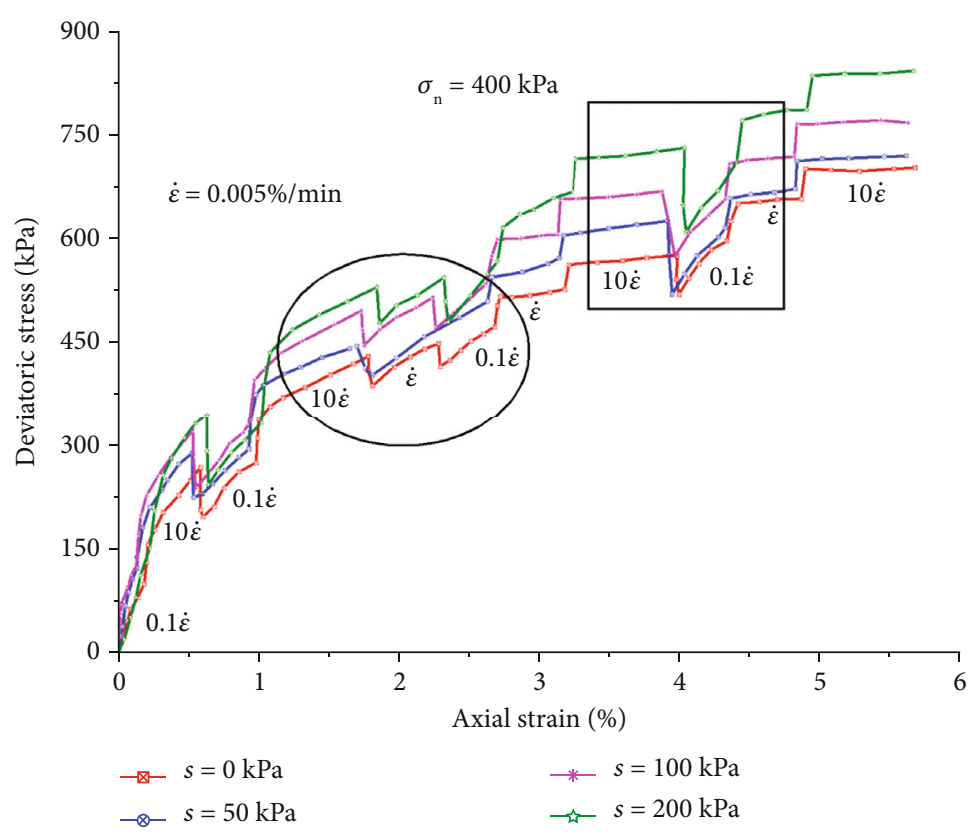

Figure 5: $\left(\sigma_{1}-\sigma_{3}\right)-\varepsilon_{a}$ summary curves $\left(\sigma_{\mathrm{n}}=400 \mathrm{kPa}\right)$.

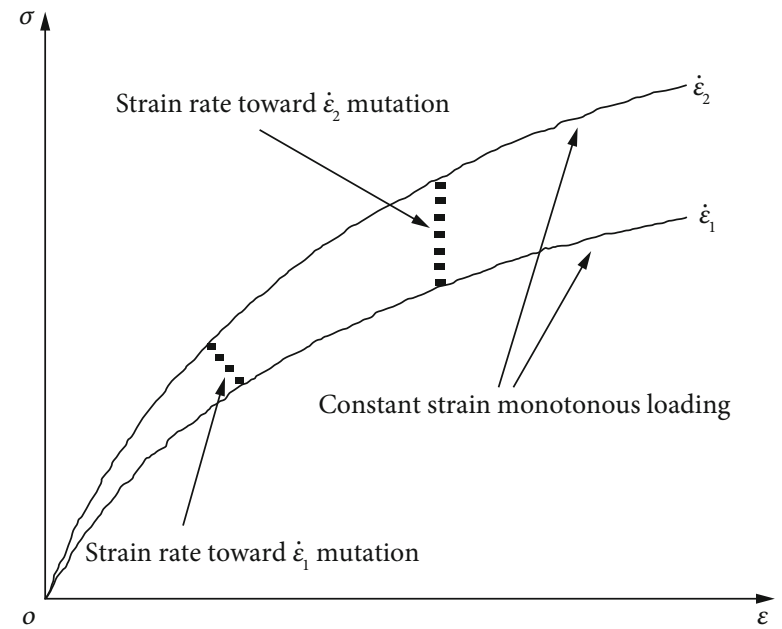

Figure 6: Isokinetic viscosity diagram.

water drained within $24 \mathrm{~h}$ was less than $0.05 \%$ of the specimen volume, the matric suction equilibration was reached [67].

(4) Loading: the net confining pressure $\sigma_{\mathrm{n}}$ and matric suction $s$ were maintained at constant values. The specimen was loaded at a variable strain rate. The sequence of variable strain rate was: $0.1 \dot{\varepsilon} \longrightarrow 10 \dot{\varepsilon}$ $\longrightarrow 0.1 \dot{\varepsilon} \longrightarrow 10 \dot{\varepsilon} \longrightarrow \dot{\varepsilon} \longrightarrow 0.1 \dot{\varepsilon} \longrightarrow \dot{\varepsilon} \longrightarrow 10 \dot{\varepsilon} \longrightarrow 0.1 \dot{\varepsilon}$ $\longrightarrow \dot{\varepsilon} \longrightarrow 10 \dot{\varepsilon}(\dot{\varepsilon}=0.005 \% / \mathrm{min})$.

\section{Results and Discussion}

3.1. Viscoplastic Parameter $\beta$ Value. Based on the viscoplastic parameter $\beta$ related to the loading rate effect, proposed by $\mathrm{Li}$ (2012) [70], the viscoplasticity of reticulate red clay was analyzed in this study. Li (2012) [70] demonstrated that the stress change is always proportional to strain rate (Figure 3) as follows:

$$
\frac{\Delta q_{a}}{q_{a}}=\frac{\left(q_{a 2}-q_{a 1}\right)}{q_{a 1}}=\beta \log \left(\frac{\varepsilon_{a 2}{ }^{i r}}{\varepsilon_{a 1}{ }^{i r}}\right),
$$

where $q_{a 1}, q_{a 2}, \varepsilon_{a 1}^{i r}$, and $\varepsilon_{a 2}^{i r}$ are the axial stresses and irreversible axial strain rates before and after a change in the strain rate, respectively, and $\beta$ is the viscoplastic parameter.

$\mathrm{Li}$ (2012) [70] analyzed the experiment results and found that the total strain rate has the following relationship with the irreversible part:

$$
\frac{\varepsilon_{a 1}{ }^{i r}}{\varepsilon_{a 2}{ }^{i r}} \cong \frac{\varepsilon_{a 2}^{\cdot}}{\varepsilon_{a 1}^{\cdot}}
$$

where $\varepsilon_{a 1}^{\cdot}$ and $\dot{\varepsilon}_{a 2}$ are the total axial strain rates before and after a change in the strain rate.

The $\beta$ value was calculated using the following equation.

$$
\frac{\Delta q_{a}}{q_{a}}=\frac{\left(q_{a 2}-q_{a 1}\right)}{q_{a 1}}=\beta \log \left(\frac{\varepsilon_{a 2}^{\cdot}}{\dot{\varepsilon_{a 1}}}\right) .
$$

The specific method for obtaining $\Delta q_{a}, q_{a 1}, q_{a 2}, \varepsilon_{a 1}^{\cdot}$, and $\varepsilon_{a 2}^{\cdot}$ is shown in Figure 3.

3.2. Analysis of Viscoplastic Test Results. From the viscoplastic test data of reticulate red clay, the relationship curves of the deviator stress $\left(\sigma_{1}-\sigma_{3}\right)$ and the axial strain $\left(\varepsilon_{a}\right)$ of the soil specimens at all levels of suction and net confining pressure were obtained as shown in Figures 4 and 5. Figure 6 shows the isokinetic viscosity diagram. 


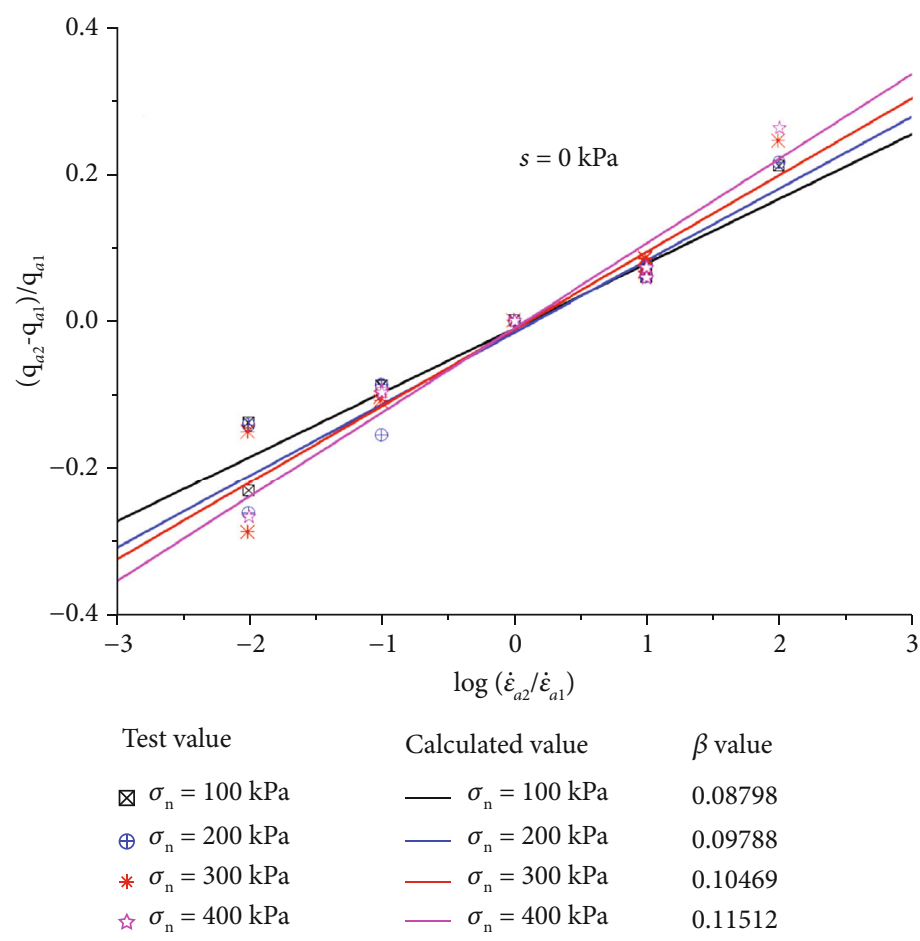

FIGURE 7: $\beta$ value of reticulate red clay with different net confining pressure $(s=0 \mathrm{kPa})$.

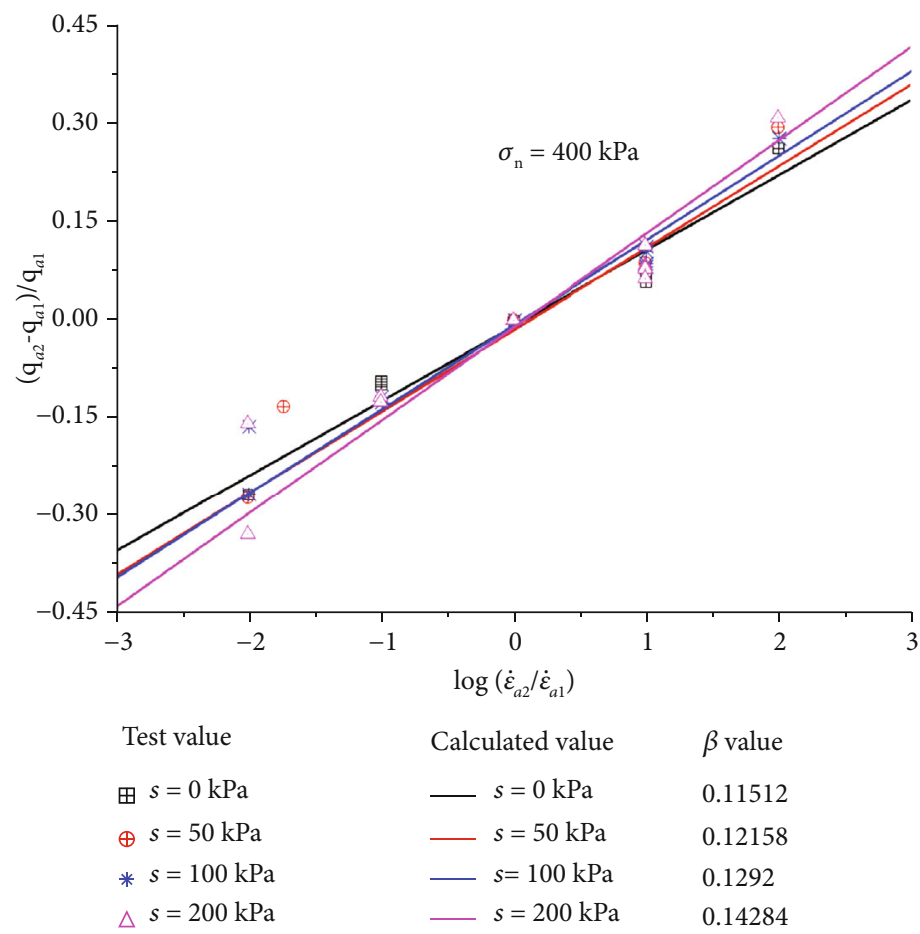

Figure 8: $\beta$ value of reticulate red clay with different matric suction $\left(\sigma_{\mathrm{n}}=400 \mathrm{kPa}\right)$.

It is observed in Figures 4 and 5 that under the triaxial test conditions, both the saturated and unsaturated remolded reticulate red clay specimens show obvious loading rate effects during loading. That is, the stress-strain curve mutates upward when the loading rate suddenly increases, and the stress-strain curve mutates downward when the loading rate suddenly decreases. In the test range, the stress-strain curves of reticulate red clay with different 


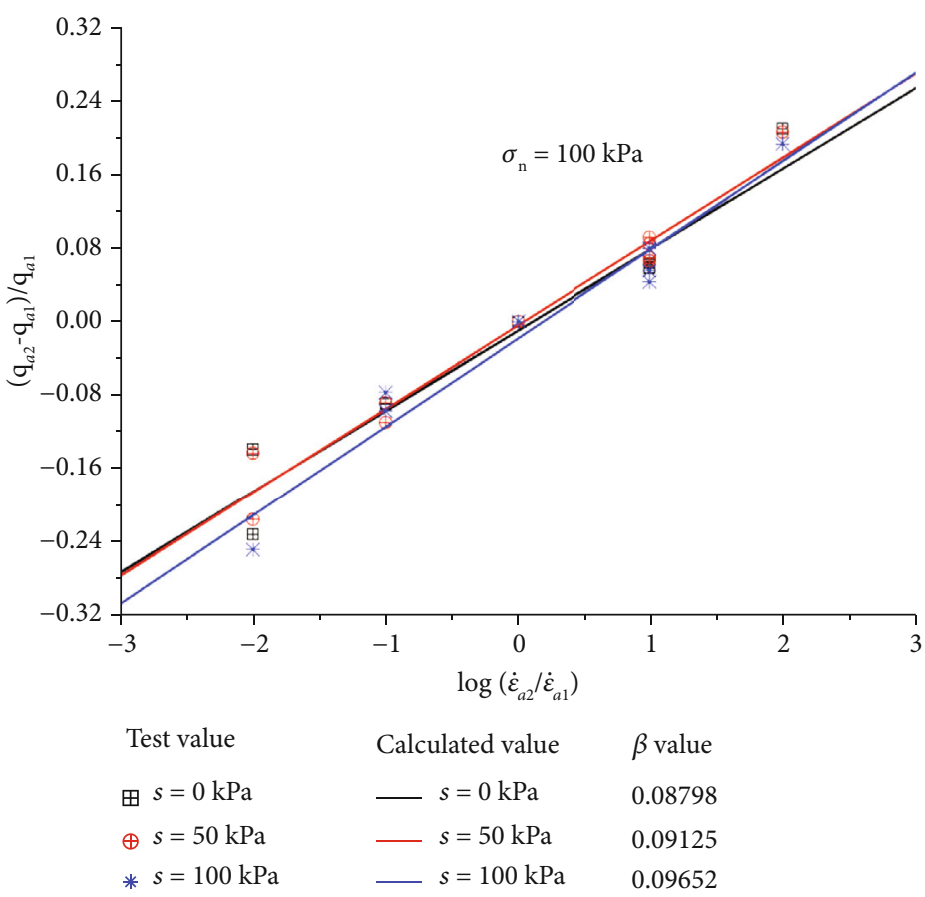

Figure 9: $\beta$ value of reticulate red clay with different matric suction $\left(\sigma_{\mathrm{n}}=100 \mathrm{kPa}\right)$.

TABle 3: Viscoplastic parameter $\beta$ values under different test conditions.

\begin{tabular}{lcccc}
\hline No. & $\begin{array}{c}\sigma_{\mathrm{n}} \\
(\mathrm{kPa})\end{array}$ & $\begin{array}{c}s \\
(\mathrm{kPa})\end{array}$ & $\begin{array}{c}\text { Viscoplastic } \\
\text { parameter } \beta\end{array}$ & $\begin{array}{c}\text { Regression } \\
\text { coefficients }\end{array}$ \\
\hline R1-1 & 100 & 0 & 0.088 & 0.941 \\
R1-2 & 200 & 0 & 0.098 & 0.920 \\
R1-3 & 300 & 0 & 0.105 & 0.928 \\
R1-4 & 400 & 0 & 0.115 & 0.945 \\
R2-1 & 400 & 0 & 0.115 & 0.945 \\
R2-2 & 400 & 50 & 0.122 & 0.929 \\
R2-3 & 400 & 100 & 0.129 & 0.991 \\
R2-4 & 400 & 200 & 0.143 & 0.966 \\
R3-1 & 100 & 0 & 0.088 & 0.941 \\
R3-2 & 100 & 50 & 0.091 & 0.967 \\
R3-3 & 100 & 100 & 0.097 & 0.950 \\
\hline
\end{tabular}

saturations are all in isotach. It is also observed that under the same matric suction level, the corresponding stiffness of reticulate red clay under the same strain was greater with greater net confining pressure. At the same net confining pressure level, the corresponding stiffness of reticulate red clay under the same strain was greater with greater matric suction. The stiffness of the specimen was evidently improved with increased matric suction. Thus, in the process of rainfall, the matric suction in reticulate red clay decreases, and the stiffness of the soil body decreases gradually, because reticulate red clay absorbs water and moves from an unsaturated state to a saturated state.

Comparing the two areas indicated by the circles and rectangles in Figures 4 and 5, the process of the strain rate is from $10 \dot{\varepsilon} \longrightarrow \dot{\varepsilon} \longrightarrow 0.1 \dot{\varepsilon}(\dot{\varepsilon}=0.005 \% / \mathrm{min})$ in the area cov- ered by the circle, and the process of the strain rate is from $10 \dot{\varepsilon} \longrightarrow 0.1 \dot{\varepsilon}(\dot{\varepsilon}=0.005 \% / \mathrm{min})$ in the area covered by the rectangle. It is found that the slope of the stress-strain curve corresponding to the strain rate $0.1 \dot{\varepsilon}$ in the area covered by the circle is smaller than that in the area covered by the rectangle. The loading sequence has an effect on the stress-strain change process.

As observed in Figure 6, the stress-strain relationship mutates correspondingly when the strain rate of the specimen changes abruptly, and this mutation is permanent rather than instantaneous. As loading proceeds, the stress-strain relationship is closer to the stress-strain relationship of the strain rate after mutation, until the strain rate changes again. During testing, the stress-strain curves of specimens at different loading stages with the same strain rate can be normalized into the same curve. Thus, under monotonic loading, the effective stress can be indicated as a single-value function of the irrecoverable strain and its strain rate.

3.3. Calculation and Analysis of Viscoplastic Parameter $\beta$. The viscoplastic parameter $\beta$ value of reticulate red clay in different net confining pressure and matric suction conditions is shown in Figures 7-9.

It is observed from Figures 7, 8, and 9 that even under different test conditions, there is a linear relationship between $\left(q_{a 2}-q_{a 1}\right) / q_{a 1} \sim \log \left(\varepsilon_{a 2}^{\cdot} / \varepsilon_{a 1}^{\cdot}\right)$ in the process of testing. This shows that the solution of the viscosity parameter $\beta$ of reticulate red clay in different test conditions is satisfied in Eq. (3). In addition, it is observed in Figure 7 that under the same water content and saturation conditions, the viscoplastic parameter $\beta$ value of the saturated specimen increases with increasing net confining pressure; that is, the viscoplasticity of reticulate red clay under the condition of high net confining pressure is stronger than under low net confining 


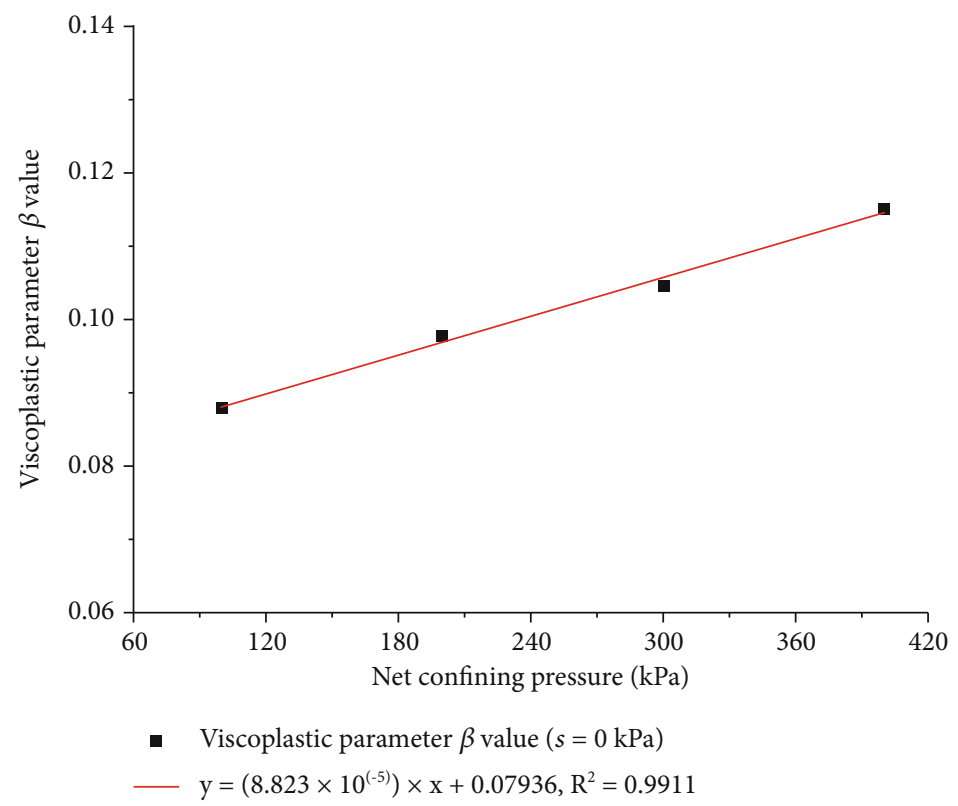

FIgURE 10: Relationship between $\beta$ value of reticulate red clay and net confining pressure

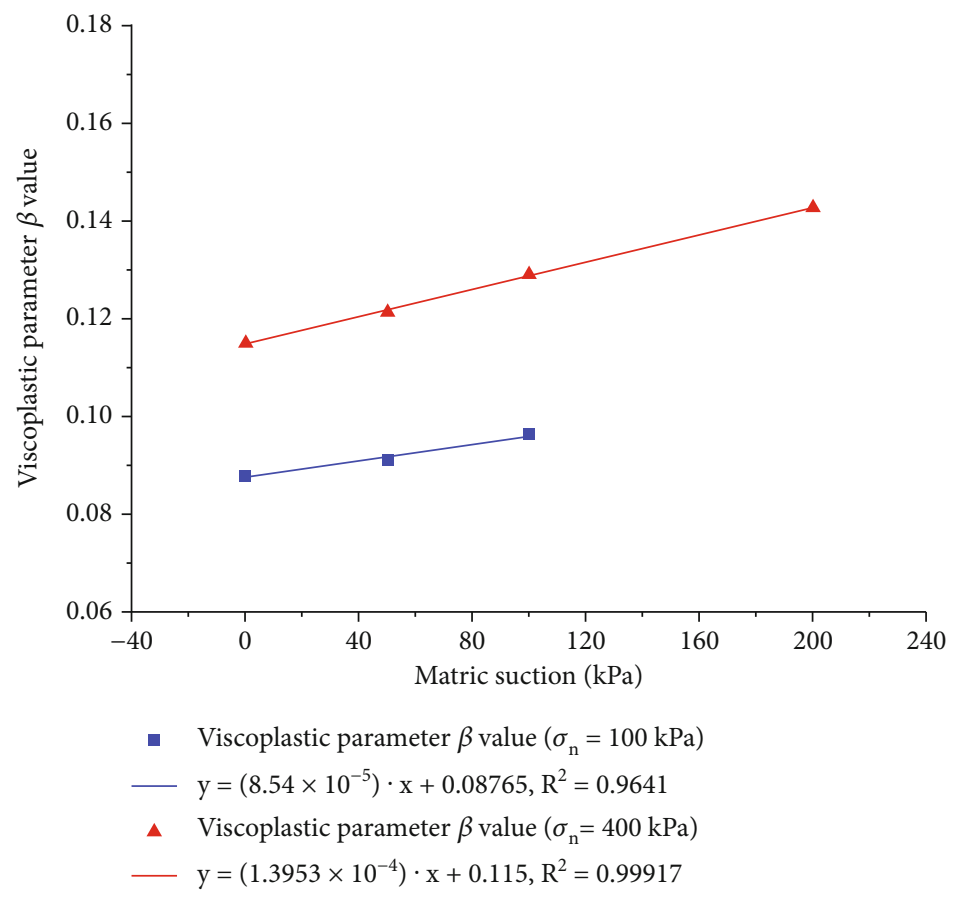

FIGURE 11: Relationship between $\beta$ value of reticulate red clay and matric suction.

pressure. It is also observed from Figures 8 and 9 that under the condition of constant net confining pressure, the viscoplastic parameter $\beta$ value of the specimen is greater when a greater matric suction is applied to the specimen, indicating that reticulate red clay has a more obvious viscoplasticity when the matric suction is greater.

According to Eq. (3) and the extraction method for each parameter in Figure 3, the viscoplastic parameter $\beta$ value of reticulate red clay and the corresponding linear regression coefficient under different test conditions are shown in
Table 3. From Table 3, the change in the viscoplastic parameter $\beta$ in each group test can be understood more readily. The conditions of each test are different, but the linear regression coefficients of the viscoplastic parameter $\beta$ values for each test are high, further illustrating that Eq. (3) is suitable for solving the viscoplastic parameter $\beta$ of reticulate red clay under different experimental conditions.

The relationship between the $\beta$ value of reticulate red clay, net confining pressure, and matric suction are shown in Figures 10 and 11. 


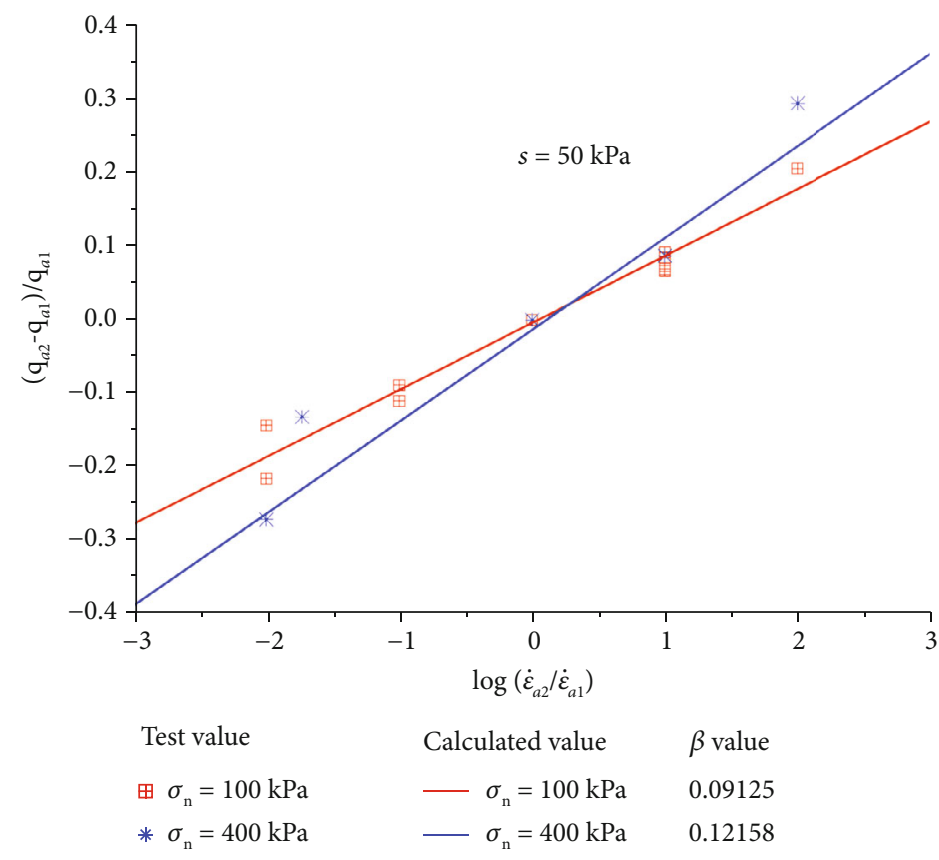

FIGURE 12: $\beta$ value of reticulate red clay with different confining pressure $(s=50 \mathrm{kPa})$.

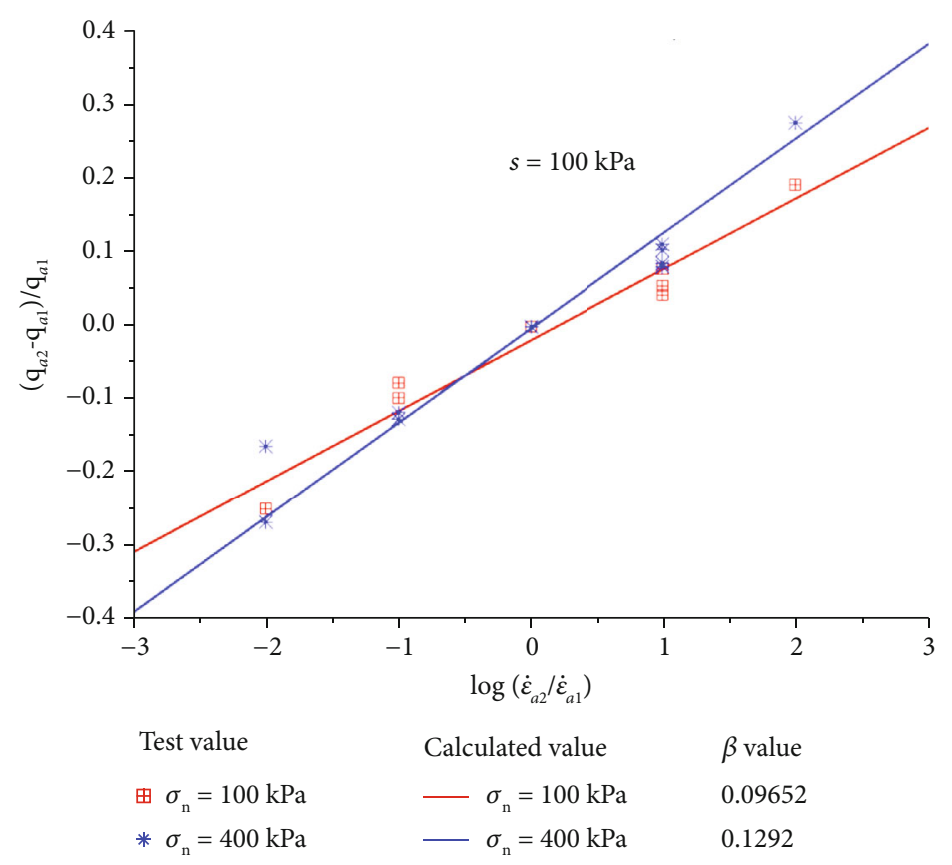

FiguRe 13: $\beta$ value of reticulate red clay with different confining pressure $(s=100 \mathrm{kPa})$.

Figure 10 shows that there is a linear relationship between the viscoplastic parameter $\beta$ of reticulate red clay and the net confining pressure. The fitting equation for the net confining pressure and viscoplastic parameter $\beta$ can be obtained from Figure 10.

When $s=0 \mathrm{kPa}$,

$$
\beta=\left(8.823 \times 10^{-5}\right) \times\left(\sigma_{3}-\mu_{a}\right)+0.07936
$$

Figure 11 shows that the viscoplastic parameter $\beta$ of unsaturated reticulate red clay increases with increasing net confining pressure. There is a linear relationship between the viscoplastic parameter $\beta$ of reticulate red clay and the matric suction. The fitting equation for the matric suction and viscoplastic parameter $\beta$ can be obtained from Figure 11 . When $\sigma_{\mathrm{n}}=100 \mathrm{kPa}$,

$$
\beta=\left(8.54 \times 10^{-5}\right) \times s+0.08765 .
$$


When $\sigma_{\mathrm{n}}=400 \mathrm{kPa}$,

$$
\beta=\left(1.3953 \times 10^{-4}\right) \times s+0.115 .
$$

To verify these conclusions, the R2-2, R2-3, R3-2, and R3-3 test data were processed. We can obtain the relationship $\left(q_{a 2}-q_{a 1}\right) / q_{a 1} \sim \log \left(\varepsilon_{a 2}^{\cdot} / \varepsilon_{a 1}^{\cdot}\right)$ as shown in Figures 12 and 13.

It is observed in Figures 12 and 13 that under constant matric suction, the $\beta$ value of the specimen increases with increasing net confining pressure. In other words, the viscoplasticity of reticulate red clay under the condition of high net confining pressure is stronger than under low net confining pressure, thus validating the test results.

\section{Conclusions}

Owing to their low permeability, self-healing by swelling, low cost, and high adsorption capacity, clays such as red clay can be used in seepage control systems in contaminated sites. Triaxial experiments were performed on a reticulate red clay in this study. It was found that unsaturated reticulate red clay has an evident viscoplastic nature, which is affected by the matric suction and net confining pressure. The following are the conclusions of this study.

Saturated and unsaturated reticulate red clay specimens show an obvious loading rate effect during loading under the triaxial test conditions. This study demonstrated that reticulate red clay under different saturation and different net confining pressure has similar viscoplasticity during loading. The stress-strain curves were isochronic. For the same matric suction level, the corresponding stiffness of reticulate red clay under the same strain was greater with greater net confining pressure. For the same net confining pressure level, the corresponding stiffness of reticulate red clay under the same strain was greater with greater matric suction. In the loading tests with variable strain rates, the stress-strain relationships of reticulate red clay with different saturations were affected by the changing loading sequence. Based on the obtained $\beta$ value of reticulate red clay and the corresponding linear regression coefficient, Eq. (3) is suitable for obtaining the $\beta$ values of reticulate red clay under different experimental conditions. The viscoplastic parameter $\beta$ of the specimens increases with increasing net confining pressure under the same water content and saturation conditions. There is a linear relationship between the viscoplastic parameter $\beta$ and the net confining pressure. The viscoplastic parameter $\beta$ of the specimens increases with increasing matric suction under the condition of constant net confining pressure. There is also a linear relationship between the viscoplastic parameter $\beta$ and the matric suction. Thus, the research provides significant insights for analyzing the effect of loading rate on the viscoplasticity of unsaturated reticulate red clay. These results may be beneficial in the design of compacted clay barriers in landfills.

\section{Data Availability}

The data used to support the findings of this study are available from the corresponding author upon request.

\section{Conflicts of Interest}

The authors declare that they have no conflicts of interest.

\section{Acknowledgments}

The authors are grateful for the support provided by the National Natural Science Foundation of China (Grant No. 41572269 \& 41807253), the Fundamental Research Funds for the Central Universities of Central South University (Grant No. 2018zzts202), and the Funded by Open Research Fund Program of Key Laboratory of Metallogenic Prediction of Nonferrous Metals and Geological Environment Monitoring (Central South University), Ministry of Education (2019YSJS24) for this research work.

\section{References}

[1] A. Khoshand, A. H. Bafrani, M. Zahedipour, S. A. Mirbagheri, and M. Ehtehsami, "Prevention of landfill pollution by multicriteria spatial decision support systems (MC-SDSS): development, implementation, and case study," Environmental Science \& Pollution Research International, vol. 25, no. 8, pp. 1-17, 2018.

[2] Y. He, B. B. Li, K. N. Zhang, Z. Li, Y. G. Chen, and W. M. Ye, "Experimental and numerical study on heavy metal contaminant migration and retention behavior of engineered barrier in tailings pond," Environmental Pollution, vol. 252, pp. 10101018, 2019.

[3] Y. He, K. N. Zhang, and D. Y. Wu, "Experimental and modeling study of soil water retention curves of compacted bentonite considering salt solution effects," Geofluids, vol. 2019, Article ID 4508603, 11 pages, 2019.

[4] Y. He, W. M. Ye, Y. G. Chen, K. N. Zhang, and D. Y. Wu, "Effects of $\mathrm{NaCl}$ solution on the swelling and shrinkage behavior of compacted bentonite under one-dimensional conditions," Bulletin of Engineering Geology and the Environment, vol. 79, no. 1, pp. 399-410, 2020.

[5] K. Joshik, C. Kechavarzi, K. Sutherland, K. Soga, and P. Tedd, "Laboratory and in situ tests for long-term hydraulic conductivity of a cement-bentonite cutoff wall," Journal of Geotechnical and Geo-environmental Engineering, vol. 136, no. 4, pp. 562-572, 2010.

[6] I. V. K. Nayanthika, D. T. Jayawardana, N. J. G. J. Bandara, P. M. Manage, and R. M. T. D. Madushanka, "Effective use of iron-aluminum rich laterite based soil mixture for treatment of landfill leachate," Waste Management, vol. 74, pp. 347-361, 2018.

[7] Y. He, Y. G. Chen, K. N. Zhang, W. M. Ye, and D. Y. Wu, "Removal of chromium and strontium from aqueous solutions by adsorption on laterite," Archives of Environmental Protection, vol. 45, no. 3, pp. 11-20, 2019.

[8] M. Boudali, S. Leroueil, and B. R. S. Murthy, "Viscous behaviour of natural clays," in International Conference on Soil Mechanics and Foundation Engineering, pp. 411-416, New Delhi, India, 1994.

[9] S. F. Brown, R. F. Overy, and M. P. O'Reilly, "Viscous effects observed in tests on an anisotropically normally consolidated silty clay," Géotechnique, vol. 39, no. 1, pp. 153-158, 1989. 
[10] G. Imai, "One-dimensional consolidation modeling based on the isotach law for normally consolidated clays," Soils and Foundations, vol. 43, no. 4, pp. 173-188, 2008.

[11] J. H. Zhang, J. H. Peng, A. S. Zhang, and J. Li, "Prediction of Permanent Deformation for Subgrade Soils under Traffic Loading in Southern China," International Journal of Pavement Engineering, pp. 1-10, 2020.

[12] H. D. Benedetto, F. Tatsuoka, and M. Ishihara, “Time-dependent deformation characteristics of sand and their constitutive modeling," Soils Foundations, vol. 42, no. 2, pp. 1-22, 2002.

[13] J. H. Peng, J. H. Zhang, J. Li, Y. S. Yao, and A. S. Zhang, "Modeling humidity and stress-dependent subgrade soils in flexible pavements," Computers and Geotechnics, vol. 120, 2020.

[14] N. Lu and J. L. William, Unsaturated Soil Mechanics, Higher Education Press, Beijing, 1th edition, 2012.

[15] M. H. Huang and D. Li, "A One-Dimensional FractionalDerivative Viscoelastic Model for the Aquitard Consolidation of an Aquifer System," Geofluids, vol. 2019, Article ID 5685134, 11 pages, 2019.

[16] J. M. Duncan, "Limitations of conventional analysis of consolidation settlement," Journal of Geotechnical Engineering, vol. 119, no. 9, pp. 1333-1359, 1993.

[17] F. Tatsuoka, M. Ishihara, H. Di Benedetto, and R. Kuwano, "Time-dependent shear deformation characteristics of geomaterials and their simulation," Soils and Foundations, vol. 42, no. 2, pp. 103-129, 2002.

[18] R. J. Cuss, C. C. Graham, A. C. Wiseall, and J. F. Harrington, "Cyclic loading of an idealized clay-filled fault: comparing hydraulic flow in two clay gouges," Geofluids, vol. 16, no. 3, pp. 552-564, 2016.

[19] S. Murayama, K. Michihiro, and T. Sakagami, "Creep characteristics of sands," Soils and Foundations, vol. 24, no. 2, pp. 1-15, 1984.

[20] H. Di Benedetto and F. Tatsuoka, "Small strain Behavior of geomaterials: modelling of strain rate effects," Soils Foundations, vol. 37, no. 2, pp. 127-138, 1997.

[21] P. Lade and C. T. Liu, "Experimental study of drained creep behavior of sand," Journal Engineering Mechanics, vol. 124, no. 8, pp. 912-920, 1998.

[22] R. Kuwano and R. J. Jardine, "On measuring creep behaviour in granular materials through triaxial testing," Canadian Geotechnical Journal, vol. 39, no. 5, pp. 1061-1074, 2002.

[23] H. Nawir, F. Tatsuoka, and R. Kuwano, "Experimental evaluation of the viscous properties of sand in shear," Soils and Foundations, vol. 43, no. 6, pp. 13-31, 2003.

[24] Y. He, Z. Li, K. N. Zhang, W. M. Ye, and Y. G. Chen, "Effect of $\mathrm{CuSO}_{4}$ on the hydromechanical behavior of compacted tailings," Mine Water and the Environment, vol. 39, pp. 103$111,2020$.

[25] F. Tatsuoka, "Effects of Viscous Properties and Ageing on the Stress-Strain Behaviour of Geomaterials," Proc GI-JGS workshop. ASCE Geotechnical SPT, K. Yamamuro, Ed., 2004.

[26] E. E. Alonso, A. Gens, and A. Josa, "A constitutive model for partially saturated soils," Geotechnique, vol. 40, no. 3, pp. 405-430, 1990.

[27] S. J. Wheeler, D. Gallipoli, and M. Karstunen, "Comments on use of the Barcelona Basic Model for unsaturated soils," International Journal for Numerical \& Analytical Methods in Geomechanics, vol. 26, no. 15, pp. 1561-1571, 2002.
[28] D. G. Fredlund and N. R. Morgenstern, "Stress state variables for unsaturated soils," Journal of the Geotechnical Engineering Division, vol. 103, no. 5, 1978.

[29] D. G. Fredlund, "A diffused air volume indicator for unsaturated soils," Canadian Geotechnical Journal, vol. 12, no. 4, pp. 533-539, 1975.

[30] D. G. Fredlund and N. R. Morgenstern, "Constitutive relations for volume change in unsaturated soils," Canadian Geotechnical Journal, vol. 13, no. 3, pp. 261-276, 1976.

[31] D. G. Fredlund, N. R. Morgenstern, and R. A. Widger, "The shear strength of unsaturated soils," Canadian Geotechnical Journal, vol. 15, no. 3, pp. 313-321, 1978.

[32] D. G. Fredlund, "Second Canadian Geotechnical Colloquium: appropriate concepts and technology for unsaturated soils," Canadian Geotechnical Journal, vol. 16, no. 1, pp. 121-139, 1979.

[33] D. G. Fredlund, "Consolidation of unsaturated porous media," Proceedings of the NATO Advanced Study Institute, Mechanics of Fluid in Porous Media, , pp. 525-577, University of Delaware, USA, 1982.

[34] D. G. Fredlund and H. Rahardjo, Soil Mechanics for Unsaturated Soil, Wiley, New York, NY, 1993.

[35] A. Gens, "Soil-environment interactions in geotechnical engineering," Géotechnique, vol. 60, no. 1, pp. 3-74, 2010.

[36] H. Sekiguchi, "Rheological characteristics of clays," in 9th international conference on soil mechanics and foundation engineering, vol. 1, pp. 289-292, Tokyo, 1977.

[37] W. M. Wang, L. J. Sluys, and R. de Borst, "Viscoplasticity for instabilities due to strain softening and strain-rate softening," International Journal for Numerical Methods in Engineering, vol. 40, no. 20, pp. 3839-3864, 1997.

[38] P. Perzyna, "Fundamental problems in viscoplasticity," Advances in Applied Mechanics, vol. 9, no. 2, pp. 244-368, 1966.

[39] Y. Qiao, A. Ferrari, L. Laloui, and W. Ding, "Nonstationary flow surface theory for modeling the viscoplastic behaviors of soils," Computers and Geotechnics, vol. 76, pp. 105-119, 2016.

[40] V. D. Gennaro and J. M. Pereira, "A viscoplastic constitutive model for unsaturated geomaterials," Computers and Geotechnics, vol. 54, pp. 143-151, 2013.

[41] A. Casacrande and S. D. Wilson, "Effect of rate of loading on the strength of clays and shales at constant water content," Géotechnique, vol. 2, no. 3, pp. 251-263, 1951.

[42] A. M. Richardson and R. V. Whitman, "Effect of strain-rate upon undrained shear resistance of a saturated remoulded fat clay," Géotechnique, vol. 13, no. 4, pp. 310-324, 1963.

[43] G. LeBoeuf and D. Lefebvre, "Rate effects and cyclic loading of sensitive clays," Journal of Geotechnical Engineering, vol. 113, no. 5, pp. 476-489, 1987.

[44] J. Zhu and J. Yin, "Strain-rate-dependent stress-strain behavior of overconsolidated Hong Kong marine clay," Canadian Geotechnical Journal, vol. 37, no. 6, pp. 1272-1282, 2000.

[45] J. A. Díazrodríguez, J. J. Martínezvasquez, and J. C. Santamarina, "Strain-rate effects in Mexico City soil," Journal of Geotechnical \& Geoenvironmental Engineering, vol. 135, no. 2, pp. 300-305, 2009.

[46] J. G. Zhu, J. H. Yin, and S. T. Luk, "Time-dependent stressstrain behavior of soft Hong Kong marine deposits," Geotechnical Testing Journal, vol. 22, no. 2, pp. 118-126, 1999.

[47] F. Tatsuoka, H. di Benedetto, T. Enomoto, S. Kawabe, and W. Kongkitkul, "Various viscosity types of geomaterials in 
shear and their mathematical expression," Soils and Foundations, vol. 48, no. 1, pp. 41-60, 2008.

[48] J. A. Yamamuro, A. E. Abrantes, and P. V. Lade, "Effect of strain rate on the stress-strain behavior of sand," Journal of Geotechnical \& Geoenvironmental Engineering, vol. 137, no. 12, pp. 1169-1178, 2011.

[49] R. Alzubaidi and S. H. Lafta, "Effect of strain rate on the strength characteristics of soil-lime mixture," Geotechnical and Geological Engineering, vol. 31, no. 4, pp. 1317-1327, 2013.

[50] Z. Yin, J. Yin, and H. Huang, "Rate-dependent and long-term yield stress and strength of soft Wenzhou marine clay: experiments and modeling," Marine Geotechnology, vol. 33, no. 1, pp. 79-91, 2013.

[51] K. R. Devi, R. B. Sahu, and S. Mukherjee, "Response of organic clay under cyclic loading," International Journal of Geotechnical Engineering, vol. 8, no. 2, pp. 130-143, 2014.

[52] J. Xiao, C. H. Juang, C. Xu, X. Li, and L. Wang, "Strength and deformation characteristics of compacted silt from the lower reaches of the Yellow River of China under monotonic and repeated loading," Engineering Geology, vol. 178, no. 8, pp. 49-57, 2014.

[53] N. R. Bhuria and A. Sachan, "Shear strength and constant rate of strain consolidation behaviour of cement-treated slurryconsolidated soft soil," Current Science, vol. 106, no. 7, pp. 972-979, 2014.

[54] R. V. Whitman and K. A. Healy, "Shear strength of sands during rapid loadings," Transactions, vol. 128, 1963.

[55] F. L. Peng, F. L. Li, J. Z. Li, and F. Tatsuoka, "Loading rate effects on stress-strain relation of sandy soils," Rock and Soil Mechanics, vol. 28, pp. 16-20, 2007.

[56] J. Z. Li, F. L. Peng, and F. Tatsuoka, "Viscoplastic properties of clay and constitutive model," Rock and Soil Mechanics, vol. 26, no. 6, pp. 915-919, 2005.

[57] D. G. Fredlund, "Unsaturated soil mechanics in engineering practice," Journal of Geotechnical \& Geoenvironmental Engineering, vol. 132, no. 3, pp. 286-321, 2006.

[58] C. Y. Ku, C. Y. Liu, Y. Su, and J. E. Xiao, "Modeling of transient flow in unsaturated geomaterials for rainfall-induced landslides using a novel spacetime collocation method," Geofluids, vol. 2018, 16 pages, 2018.

[59] Z. H. Zhang, X. Y. Huang, W. Liu, and L. Wang, "Study on the hydraulic parameters of woshaxi landslide soils during water level drawdown of three gorges reservoir," Geofluids, vol. 2020, Article ID 6283791, 14 pages, 2020.

[60] G. E. Veyera, Uniaxial Stress-Strain Behavior of Unsaturated Soils at High Strain Rates, Wright Laboratory, Flight Dynamics Directorate, Tyndall AFB, FL, USA, 1994.

[61] B. E. Martin, W. Chen, B. Song, and S. A. Akers, "Moisture effects on the high strain-rate behavior of sand," Mechanics of Materials, vol. 41, no. 6, pp. 786-798, 2009.

[62] J. C. Rojas, C. Mancuso, M. Hamza, M. Shahien, and Y. Elmossallamy, "Effect of loading rate on the behaviour of unsaturated soils," in International Conference on Soil Mechanics and Geotechnical Engineering: The Academia and Practice of Geotechnical Engineering, pp. 5-9, Alexandria, Egypt, 2009.

[63] Y. F. David and D. G. Fredlund, "Strain rates for unsaturated soil shear strength testing," in proceeding of the seventh Southest Asian geotechnical conference, vol. 1, pp. 787-803, Hong Kong, 1982.
[64] B. B. K. Huat, F. H. Ali, and F. H. Choong, "Effect of loading rate on the volume change behavior of unsaturated residual soil," Geotechnical \& Geological Engineering, vol. 24, no. 6, pp. 1527-1544, 2006.

[65] V. D. Gennaro and J. M. Pereira, "Viscoplastic Modelling of Unsaturated Geomaterials," in 12th International Conference of International Association for Computer Methods and Advances in Geomechanics (IACMAG), pp. 2232-2241, Goa, India, October 2008.

[66] J. Z. Li, F. L. Peng, and L. S. Xu, "One-dimensional viscous behavior of clay and its constitutive modeling," International Journal of Geomechanics, vol. 9, no. 2, pp. 43-51, 2009.

[67] J. Li, K. Hao, and F. Peng, "Research on suction equilibrium time of unsaturated reticulate red clay," KSCE Journal Civil Engineering, vol. 22, no. 6, pp. 1-7, 2017.

[68] J. Z. Li and Y. L. Yang, "Creep behavior of unsaturated reticulate red clay under matric suction," KSCE Journal of Civil Engineering, vol. 22, no. 2, pp. 582-587, 2018.

[69] Y. B. Zhu and H. M. Yu, "Unsaturated creep behaviors of weak intercalated soils in soft rock of Badong formation," Journal of Mountain Science, vol. 12, no. 6, pp. 1460-1470, 2015.

[70] J. Z. Li, "Viscous property of clay," Advanced Materials Research, pp. 455-456, 2012. 